\title{
QUALITY OF THE PARATRANSIT SERVICE (TRICYCLE) AND ITS OPERATION IN ABA, NIGERIA: AN ANALYSIS OF CUSTOMERS' OPINIONS
}

\author{
OBIOMA R. NWAOGBE* \\ C.C. IBE** \\ S.I. UKAEGBU** \\ *obinotex@yahoo.com \\ *Department of Transport Management Technology, \\ Federal University of Technology Minna, Niger State, Nigeria \\ ${ }^{\star \star}$ Department of Transport Management Technology, \\ Federal University of Technology Owerri, Imo State, Nigeria
}

\begin{abstract}
This study examines the quality of the paratransit service and its operations in Aba, Abia State, Nigeria, with a view to identifying its challenges and contributions to informal transport and equitable service distribution to the residents of Aba. Structured questionnaires and past literature were used as sources of data. The primary data included road networks, number of trips per day by operators, operating speed, and purpose of travel, passengers' security, tricycle speed, and waiting time. The study was conducted by using two questionnaires: one for the operators and the other for tricycle users. The total number of completed questionnaires for the survey was 100 for operators and 229 for users. The sampling technique used was random sampling from several zones of the study area. Data were analysed using percentage and Chi-square statistical techniques for testing the hypotheses with the Minitab 11.0 version package. The study found that $92 \%$ of operators reported a high level of road network deterioration, and $61 \%$ reported making 9-12 trips per day. The hypothesis test was used to study people's feelings about the attributes of the service provided for paratransit users, such as affordability, regularity, comfort and safety. It was found that there is no significant difference at the $5 \%$ level between the various categories of these respondents.
\end{abstract}

\section{INTRODUCTION}

Informal transport services are notable for their role as 'gap fillers'. They exist largely to fill service voids left by formal public transport operators. Formal public transport services are rarely up to the task of completely satisfying escalating demands for travel. All too often throughout the developing world, public transport finds itself in a free-fall of deteriorating service and shrinking income. There are observations that unlicensed operators 'informally' step in and pick up passengers where public transport operators leave off because rules and regulations are not effectively enforced by transport regulators (Cervero, 1998). 
Many researchers recommend an integration of paratransit as a feeder for public transit systems to enhance performance of urban transportation (Shimazaki \& Rahman, 1996; Satiennam, Fukuda \& Oshima, 2006). This idea not only provides easy connectivity but helps in utilising existing resources - advantages that should not be overlooked. In addition, the future of public transit is based on its performance as well as how people perceive the quality of services it provides.

Paratransit operations are available not only in developing countries but also in some developed countries. The paratransit sector, generally speaking, ranges from oneperson rickshaws to 25-passenger minibuses. Many authors (Tanaboriboon \& Agad, 1990; Tanaboriboon \& Madrona, 1990; Boyle, 1994; Dourado, 1995; Cervero, 1997) have presented and discussed a wide range of paratransit services and their comparative benefits and drawbacks.

In Nigerian cities, the low level of transport services provided by conventional transport systems has led to the expansion of paratransit operations in busy corridors. Bus systems and paratransit operations are major competitors. Typically, passengers wait at the curb for a bus to arrive and paratransit operators interlope on the scheduled service; the result is that passengers will probably board the vehicle that comes first.

Low-capacity vehicles operate in many cities as an alternative to public transport in developing countries, for instance in Aba City, Abia State, Nigeria. Some examples are auto rickshaws and cycle rickshaws, responsible for $15 \%$ of the public transport market in India (Umrigar, Sikdar \& Khanna, 1991); tuk-tuks (a three-wheeled motorcycle) which are called KekeNapeps in Nigeria; while silor-leks (a small four-wheeled vehicle) play an important role in moving persons as well as goods in Bangkok, Thailand (Tanaboriboon \& Agad, 1990; Tanaboriboon \& Madrona, 1990). Dourado (1995) presents examples of other low-capacity vehicles used as passenger transportation in different cities.

\section{STUDY AREA}

Aba is one of the largest cities of Abia State, Nigeria. It is larger and more populated than the state capital, Umuahia. It is about $60 \mathrm{~km}$ south of Umuahia, the state capital. Aba comprises two local government areas, namely Aba North and Aba South. Aba South is a Local Government Area with its headquarters situated in the centre of the city. It has an area of 49 square kilometres and a population of 423852 as at the 2006 census. On the map Aba South is located at $5^{\circ} 06^{\prime} \mathrm{N} 7^{\circ} 21^{\prime} \mathrm{E} / 5.1^{\circ} \mathrm{N} 7.35^{\circ} \mathrm{E}$. Aba North is a Local Government Area with headquarters situated in the district called Eziama Uratta. It has an area of 23 square kilometres and a population of 107485 as at the 2006 census. Aba North is located at $05^{\circ} 20^{\prime} \mathrm{N} 07^{\circ} 19^{\prime} \mathrm{E} / 5.333^{\circ} \mathrm{N} 7.317^{\circ} \mathrm{E}$ (Canby, 1984). 
Aba is a commercial nerve centre of Eastern Nigeria, the home of Ariaria Market noted for home-made shoes, bags and other household items. In addition, there are the Ngwa Road Market (New Market) and the Cemetery Market, while virtually every street in Aba has its share of the business activities for which the town is known. There are a good number of both public and private industrial establishments as well as financial institutions. Moreover, Aba is surrounded by oil wells which separate it from the city of Port Harcourt, a distance of about $30 \mathrm{~km}$ away (Encyclopaedia Britannica, 2007).

Roads lead to Aba from Port Harcourt, Owerri, Umuahia, Ikot Ekpene and Ikot Abasi. Aba is served by a station and a halt (mini station) on the Nigerian railway. Aba is also a major hub for road transport in the eastern region. A large number of transport companies operate coaches that transport people daily to various parts of the country. The city is second to Onitsha in daily volume of mass transportation in the eastern part of the country. The commercial motorcycle (Okada) has been banned and, although they are still in use in some suburbs, the Okada has been replaced by tricycles in the main city. The beneficiaries of the public transport system in Aba are mostly businessmen and women due to the commercial nature of the town, although students also benefit from it. Furthermore, the public transport services in the study area are offered by private individuals and not the government.

\section{PARATRANSIT AND ITS OPPORTUNITIES IN DEVELOPING COUNTRIES}

Paratransit provides a variety of services including door-to-door movement by flexible forhire services (example KekeNapeps, taxis, motorcycles) in the city of Aba and intermediate line-haul fixed-route services by minibuses covering the entire region. Most paratransit systems are provided by the private sector and operated on public streets in mixed traffic. Paratransit services usually fall between private transport and conventional public transport.

Paratransit is considered as informal transport as it does not meet certification requirements for commuter and public-carrier vehicles. It is distinguished by its small-sized, lowperforming, ageing or unfit vehicles. Moreover, paratransit services are poorly organised which causes them to compete vigorously for passengers, have overloaded vehicles, and to pick up or drop off passengers away from designated areas, thus lowering the quality of service (Shimazaki, et al., 1996).

\section{Importance of paratransit}

Paratransit provides numerous significant benefits to urban transportation development in many cities of developing countries. They are as follows:

- Mobility: The major role of paratransit is to provide much-needed and much-valued mobility, especially for the poor and travellers who do not own or have access to private automobiles. These people depend entirely on public transport for reaching jobs, markets, schools and other destinations. 
- Source of employment: Paratransit is a source of urban employment for both young and old because it offers job opportunities for skilled and unskilled men, many of whom have migrated from rural areas (Shimazaki et al., 1996; Cervero, 2000; Vuchic, 2007). It has been reported that the paratransit sector employs about $15 \%-30 \%$ of the total workforce in many developing countries, particularly in poor cities (Tanaboriboon \& Agad, 1990; Tanaboriboon \& Madrona, 1990). Not only drivers are employed, but this sector also provides jobs for vehicle maintenance and production units.

- Complementarity: Paratransit plays an important role in high density urban areas in providing feeder connection between the neighbourhoods and trunk routes. Due to under-investment in parts of the transport infrastructures, there is difficulty in providing systematic feeder operations to normal urban transport services. Moreover, paratransit services show their compensatory role for declining intermediate line-haul public transport by offering more frequent services and guaranteed seats.

\section{Effects of paratransit}

The paratransit transport system is responsible for significant negative impacts such as traffic congestion and accidents, which harm public safety and welfare, over- competition, energy consumption and air pollution. These issues are discussed below.

- Traffic congestion: Unrestricted market entry leads to excessive supplies of service providers who, in the quest to survive in the market place, engage in over-competition. Their large numbers of vehicles reduce or slow down the traffic. They also cause bottlenecks, clogging traffic upstream especially at the main markets, bus terminals and other parts of the central business districts (Cervero, 2000). Due to the deteriorating nature of the road transport network (infrastructure) in Aba, road traffic congestion is the major challenge that faces paratransit (tricycle) operators and users.

- Public security and accidents: Due to the high level of competition in the transport sector, paratransit operators are often reckless and notorious for driving aggressively. Many of the operators are guilty of cutting off traffic to pick up customers, blocking lanes to load and discharge passengers, overloading, and ignoring traffic rules. Operating generally in mixed traffic, the low speed modes of vehicles such as KekeNapeps and taxis are prone to accidents, serious injuries and fatalities. Overloading and night journeys do not only affect children and elderly persons but also facilitate pick-pocketing and other pilfering that occur during operations.

- Cream-skimming and unprofitable services: Most of the paratransit operators try to operate only along lucrative routes and during peak periods because of perceived improved revenues and greater numbers of passengers. They leave high-cost, unprofitable services to the public transport sector. Paratransit operations take away a considerable amount of peak-hour business and make public transport operators incur deficits. In some developing cities, a large number of passengers from public buses have been lured into paratransit services as witnessed in Aba and Owerri in Nigeria. 


\section{Research questions}

The research questions were as follows:

1) How are the paratransit operators in Aba performing under the current situation of service?

2) What are the problems of the service?

3) Are there capacity constraints?

4) How much capacity is needed to satisfy the users' demands?

5) What policy options can improve the quality of service in terms of capacity, bus stops, transfer points and road networks?

6) What is your means of travelling about the city?

7) What is the name of the transport service?

8) What is your reason for travelling?

9) Do you travel from your house every day?

10) What is your reason for using public transport?

11) What distance do you walk before you get to the bus stop/terminal?

12) Is the paratransit that operates in your area affordable?

13) Are services regular?

14) Are services safe?

\section{Hypotheses}

1) $\mathrm{H}_{0}$ : There is no significant difference between the various categories of respondents in their views about the regularity of the service.

2) $\mathrm{H}_{0}$ : There is no significant difference between the various categories of respondents in their views about the affordability of the service.

3) $\mathrm{H}_{0}$ : There is no significant difference between the various categories of respondents in their views about the comfort of the service.

4) $\mathrm{H}_{0}$ : There is no significant difference between the various categories of respondents in their views about the safety of the service.

\section{METHODOLOGY}

\section{KekeNapeps (paratransit) in Aba City}

KekeNapep (tricycle) is the main mode of urban transport in Aba. It is a form of public transport for passengers and does not have a fixed schedule. KekeNapep operations in Aba are either fixed route or non-fixed route. Table 1 presents the distribution of public transport vehicles in Aba. 
Table 1: Number of public transport vehicles in Aba

\begin{tabular}{|l|l|l|l|}
\hline No & Type of services & Number of vehicles & Number of routes \\
\hline 1 & Taxi & 100 & 8 \\
\hline 2 & Bus (township bus) & 500 & 13 \\
\hline 3 & KekeNapep (tricycle) & 13512 & 36 \\
\hline 4 & Motorcycle Okada & 200 & 6 \\
\hline
\end{tabular}

(Source: Aba Township Union of Taxi, Bus, KekeNapep. August 2011)

Data used for this study were obtained through primary (structured questionnaires) and secondary (past literature) sources. The primary data collected covered operations of the paratransit transportation system (routes, travel cost, number of vehicles, number of vehicles operating per day), travel characteristics of passengers (travel time, travel cost, travel purpose, waiting time, safety of service, regularity of service and so on) and the operators' and passengers' challenges (operating cost, tax, road network, travelling time, operating speed).

The study adopted the total number of passengers in each tricycle for a single trip on a particular day as the sample frame. The average capacity of a tricycle on these routes is four passengers. The two questionnaires used for the study included one for KekeNapep drivers, and one for KekeNapep users. A random sample of respondents was selected from several places in Aba where the KekeNapep drivers usually have bases, such as hospitals, markets, schools, residential areas, terminals and road intersections. The survey was conducted for some weeks from August-October 2011. The total numbers of respondents used in this survey were 100 KekeNapep drivers and 229 KekeNapep users. Data were analysed through percentage and Chi-square statistical techniques for testing the hypotheses with Minitab 11.0 version package.

\section{Data analysis}

\section{Test of hypothesis on the affordability of the service}

Table 2 describes the respondents' report and the expected frequency of the affordability of the service. 
Table 2: Affordability of service

\begin{tabular}{|l|l|l|l|}
\hline Response & YES & NO & TOTAL \\
\hline Graduate & $48(48.70)$ & $20(19.30)$ & 68 \\
\hline Undergraduate & $39(42.97)$ & $21(17.03)$ & 60 \\
\hline ND/TC11/NCE & $34(28.65)$ & $6(11.35)$ & 40 \\
\hline $\begin{array}{l}\text { Senior Sec. Sch. Certificate/ First } \\
\text { Sch. Leaving Certificate }\end{array}$ & $43(43.69)$ & $18(17.31)$ & 61 \\
\hline Total & 164 & 65 & 229 \\
\hline
\end{tabular}

(Source: Field Survey 2011)

Chi-Sq $=0.010+0.025+$

$0.367+0.925+$

$1.001+2.524+$

$0.011+0.027=4.890$

$\mathrm{DF}=3, \underline{\mathrm{P}-\text { Value }=0.180}$

Interpretation: Since $\mathrm{P}$-value $>0.05$, we accept $\mathrm{H}_{0}$. This shows that there is no significant difference at the $5 \%$ level between the various categories of respondents in their view about the affordability of the service.

\section{Test of hypothesis on the regularity of the service}

Table 3 describes the respondents' report and the expected frequency of the regularity of the service.

Table 3: Regularity of service

\begin{tabular}{|l|l|l|l|}
\hline Response & YES & NO & TOTAL \\
\hline Graduate & $51(52.56)$ & $17(15.44)$ & 68 \\
\hline Undergraduate & $45(46.38)$ & $15(13.62)$ & 60 \\
\hline ND/TC11/NCE & $29(30.92)$ & $11(9.08)$ & 40 \\
\hline $\begin{array}{l}\text { Senior Sec. Sch. Certificate/ First } \\
\text { Sch. Leaving Certificate }\end{array}$ & $52(47.15)$ & $9(13.85)$ & 61 \\
\hline Total & 177 & 52 & 229 \\
\hline
\end{tabular}

(Source: Field Survey 2011)

Chi-Sq $=0.046+0.157+$

$0.041+0.139+$

$0.119+0.405+$

$0.499+1.699=3.105$

$\mathrm{DF}=3, \underline{\mathrm{P}-\text { Value }=0.376}$ 
Interpretation: If $\mathrm{P}$-value $>0.05 \%$, we accept $\mathrm{H}_{0}$. This shows that the difference is not significant at the $5 \%$ level between the various categories of respondents in their various views about the regularity of the service.

\section{Test of hypothesis on the comfort of the service}

Table 4 describes the respondents' report and the expected frequency of the comfort of the service.

Table 4: Comfort of service

\begin{tabular}{|l|l|l|l|}
\hline Response & YES & NO & TOTAL \\
\hline Graduate & $40(40.05)$ & $28(27.95)$ & 68 \\
\hline Undergraduate & $33(29.45)$ & $17(20.55)$ & 50 \\
\hline ND/TC11/NCE & $21(23.56)$ & $19(16.44)$ & 40 \\
\hline $\begin{array}{l}\text { Senior Sec. Sch. Certificate/ First } \\
\text { Sch. Leaving Certificate }\end{array}$ & $35(35.93)$ & $26(25.07)$ & 61 \\
\hline Total & 129 & 90 & 219 \\
\hline
\end{tabular}

(Source: Field Survey 2011)

Chi-Sq $=0.000+0.000+$

$0.427+0.613+$

$0.279+0.399+$

$0.024+0.035=1.777$

$\mathrm{DF}=3, \underline{\mathrm{P}-\text { Value }=0.620}$

Interpretation: Since the $\mathrm{P}$-value $>0.05 \%$ we accept $\mathrm{H}_{0}$. This shows that from the test there is no significant difference at the $5 \%$ level between various categories of respondents in their views about the comfort of the service.

\section{Test of hypothesis on the safety of the service}

Table 5 describes the respondents' report and the expected frequency of the safety of the service. 
Table 5: Safety of service

\begin{tabular}{|l|l|l|l|}
\hline Response & YES & NO & TOTAL \\
\hline Graduate & $30(28.21)$ & $38(39.79)$ & 68 \\
\hline Undergraduate & $26(24.89)$ & $34(35.11)$ & 60 \\
\hline ND/TC11/NCE & $18(16.59)$ & $22(23.41)$ & 40 \\
\hline $\begin{array}{l}\text { Senior Sec. Sch. Certificate/ First } \\
\text { Sch. Leaving Certificate }\end{array}$ & $21(25.31)$ & $40(35.69)$ & 61 \\
\hline Total & 95 & 134 & 229 \\
\hline
\end{tabular}

(Source; Field Survey 2011)

Chi-Sq $=0.114+0.081+$

$0.049+0.035+$

$0.119+0.084+$

$0.733+0.519=1.734$

$\mathrm{DF}=3, \underline{\mathrm{P}-\text { Value }=0.629}$

Interpretation: Since the $\mathrm{P}$-value $>0.05 \%$ we accept $\mathrm{H}_{0}$. This shows that from the test there is no significant difference at the $5 \%$ level between various categories of respondents in their views about the safety of the service.

\section{KekeNapep driver characteristics}

Out of the 100 drivers, 4\% were younger than 20 years of age; 47\% were 25-34 years old; 41\% 35-44 years old; and 7\% were older than 45 years. Education-wise, 20\% held First School Leaving Certificates, $66 \%$ held Senior Secondary Certificates, $1 \%$ held the Ordinary National Diploma, $3 \%$ of them are graduates, and $9 \%$ had had no formal education. The pie charts in Figure 1 describe the operating characteristics. 
Income Per Day

- N4000-N6000 - N2000-N4000

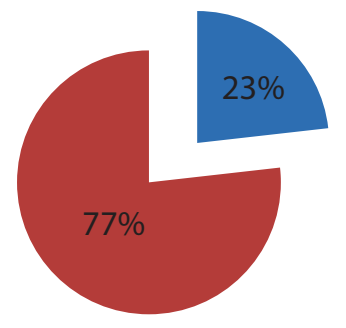

\section{Operating Cost Per Day}

- Above N1000 - N500-N1000

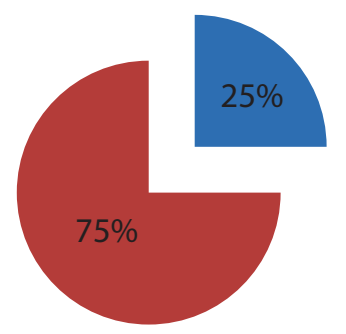

\section{Work Per Day}

- 7 days $\square$ days $\square$ days

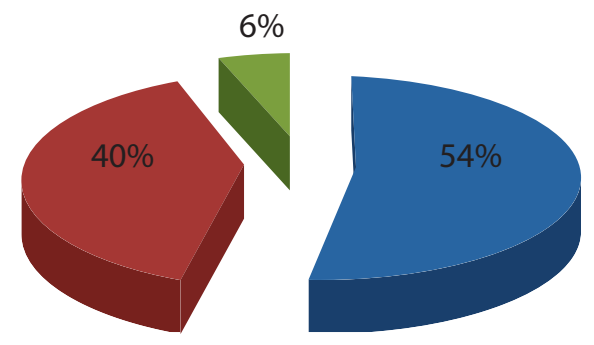

\section{Ownership of Tricycle}

n Owners - Hire Purchase $n$ Lease

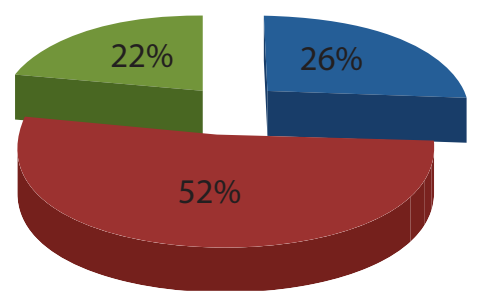

\section{Traveling Time}

-10-19mins above 20mins

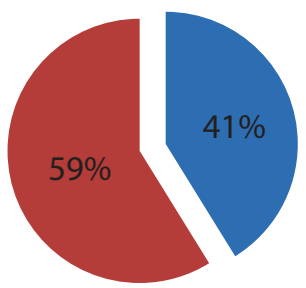

- 5-15km $\quad 16 \mathrm{~km}$ and Above

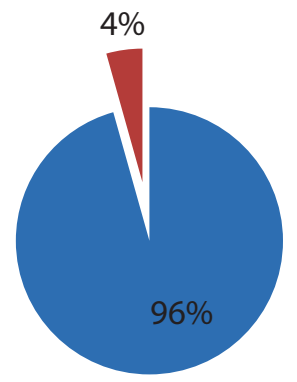

\section{Route Length}

Number of Trips Per Day

घ 4-5 Trips — 6-8 Trips — 9-12 Trips
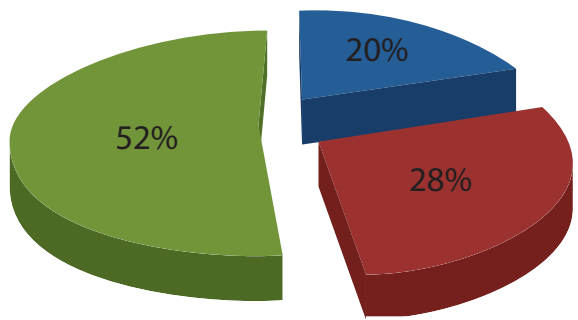

Figure 1: Operating characteristics 


\section{KekeNapep customer characteristics}

Customers who use paratransit in Aba returned 229 questionnaires. Respondents were $64 \%$ male and $36 \%$ female. The age range included $10 \%$ below the age of 15 years; $33 \%$ in the range 15-24 years; 19\% between 25 years and 34 years; 12\% from 35-44 years; 10\% aged $45-54$ years; while $16 \%$ were 55 years and above. The pie charts in Figure 2 describe the customers' characteristics.

\section{Education}

- Graduate
Undergraduate $\square$ ND $\quad$ SSCE $\square$ FSLC

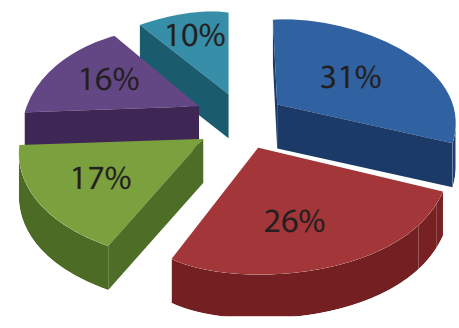

\section{Purpose of Travelling}

Work School Business

Visit
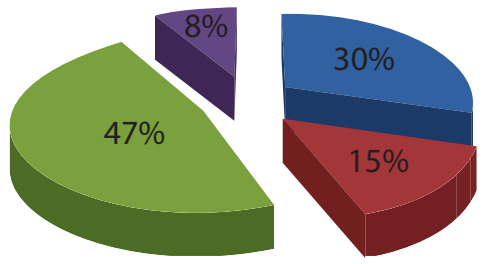

\section{Road Network}

- Poor Condition Good Condition

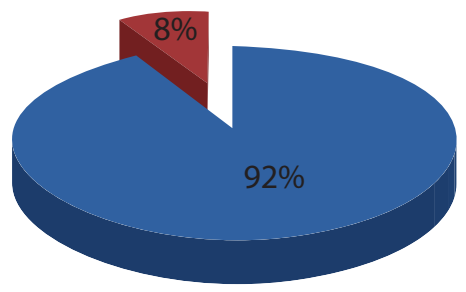

Satisfaction

- Very Satisfactory $\square$ Satisfactory $\quad$ Not Satisfactory

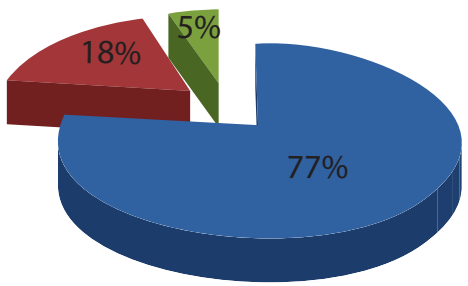

\section{Reason For Using Tricycle}

Because is Fast $\square$ Cheaper $\square$ Safer
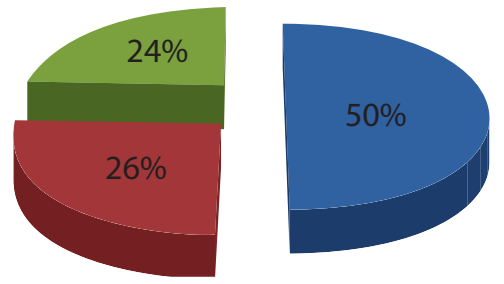

\section{Availability}

All Time $\quad$ Not all Time

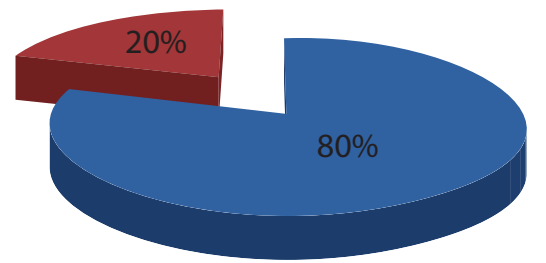

\section{Work Condition}

- Civil Servant $\quad$ Student Unemployed - Business Men/Women Technician Housewife

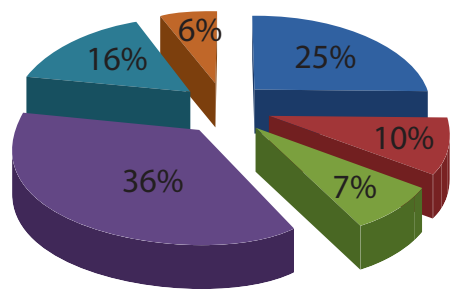

\section{Speed of Tricycle}

- Very Fast $n$ Fast $\quad$ Slow

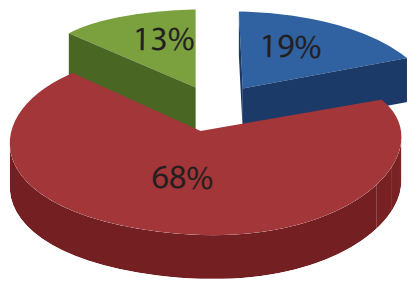




\section{Mode of Public Transport in use before Tricycle}

- Car — Bus घ Taxi — Motorcycle
Walk Distance before Getting Tricycle

- $1-2 \mathrm{~km} \quad$ - $100 \mathrm{~m}-1 \mathrm{~km} \quad$ - $50 \mathrm{~m}-100 \mathrm{~m}$
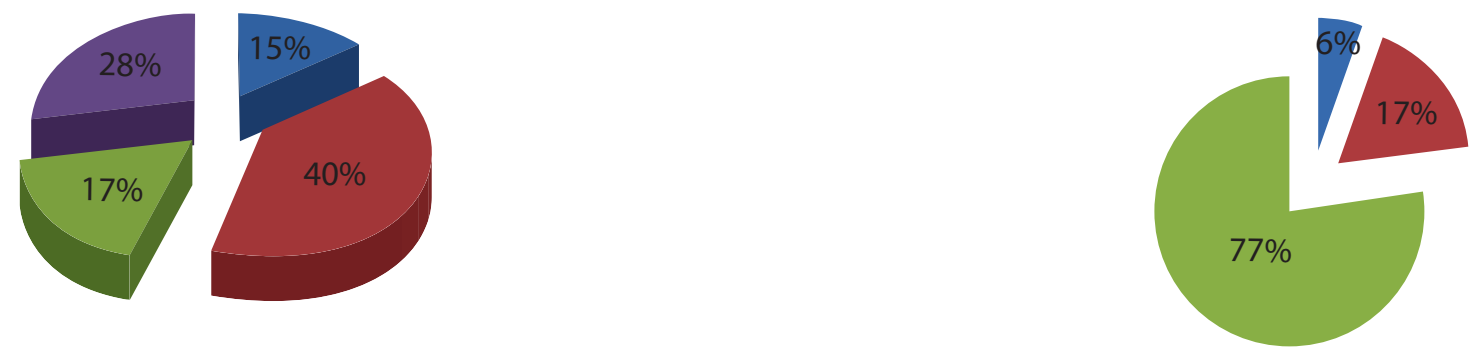

\section{Reason for Using Tricycle}

- Tricycle a Car घ Taxi घ Bus

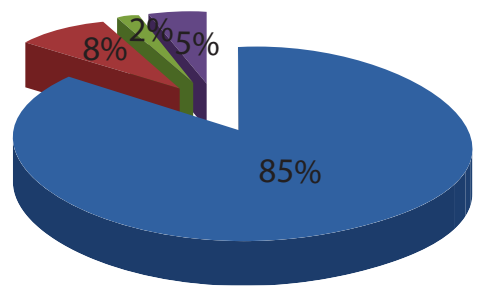

Figure 2: Customers' characteristics

\section{DISCUSSION}

From the study, it was observed that $92 \%$ of tricycle users reported a high level of poor road network, while $8 \%$ responded that the road network is good. Of the operators, $52 \%$ reported making 9-12 trips per day, 28\% reported making 6-8 trips per day, while 20\% reported making 4-5 trips per day. A total of 75\% reported that their operating cost per day is from N1000 and up, while 25\% reported that they spend between N500 and N1000 for operating costs per day. After expenses, $77 \%$ of the respondents reported that they realise between N2000 and N4000 per day, while 23\% reported that they realise between N4000 and N6000 per day. Furthermore, 54\% of the respondents reported that they work seven days per week, $40 \%$ work six days per week, while 6\% work five days per week. Distancewise, $96 \%$ of the operators travel between $5 \mathrm{~km}$ and $15 \mathrm{~km}$ per trip, while $4 \%$ responded that they travel between $16 \mathrm{~km}$ and above per trip.

Before the introduction of the tricycle, $40 \%$ of the respondents used buses for their travelling, $28 \%$ used motorcycles, $15 \%$ private cars and $17 \%$ taxis. Then after the tricycle became available, $85 \%$ of the respondents used the tricycle, $8 \%$ private cars, $2 \%$ taxis and $5 \%$ used buses for their travelling. With respect to availability, $80 \%$ of the respondents reported that the tricycle is available all the time, while $20 \%$ responded that is not. Walking distances to 
board a tricycle vary with $59 \%$ of the respondents walking between 50 and 100 metres, $31 \%$ between $100 \mathrm{~m}$ and $1 \mathrm{~km}$ and $10 \%$ between 1 and $2 \mathrm{~km}$. Most respondents were happy with how the tricycles perform: $77 \%$ were very satisfied, $18 \%$ were satisfied, while $5 \%$ were not satisfied. Half of the respondents use paratransit because it is quick and because of its meandering nature during traffic congestion.

The hypothesis test was used to study people's feelings about the attributes of the services provided for the paratransit users, such as affordability, regularity, comfort and safety. In testing the hypotheses about these attributes, there was no significant difference at the $5 \%$ level between the various categories of these respondents.

\section{CONCLUSIONS}

The operation of tricycles (paratransit) in $\mathrm{Aba}$ is one of the major means of transportation of people and goods to various parts of the city and even to the rural areas and neighbouring Local Government Areas in Ngwa land, which is the most populated area of the state. The operators of these tricycles are young and middle-aged men. From the analysis, $61 \%$ of the operators make about 9-12 trips per day. This study revealed that paratransit, both flexible for-hire and fixed-route types, shows the capability of being implemented as a feeder system to formal public transport in Aba and other areas. It also serves as a means of full public transport in the area due to the poor public transport system and poor road network in the state. The study recommended pragmatic strategies such as the provision of a good road transport network and an organised mass transit system to help the paratransit system, among others, to provide a more efficient public transport system in the study area.

The researcher also suggests that the government should devote more attention to continuous maintenance of road transport infrastructure in order to eliminate the unnecessary traffic congestion at the bridge in Ogbor Hill area, for instance, which has caused many road accidents and fatalities, and also the congestion within the central business district of the study area.

Finally, in testing the hypotheses of the study, the researcher observed that there was no significant difference between the various categories of respondents with respect to affordability, regularity, comforts and safety of the service, and therefore all the null hypotheses were accepted. 


\section{REFERENCES}

Boyle, D.K. 1994. Jitney enforcement strategies in New York. Transportation Research Record 1433, 77-186.

Canby, C. 1984. The Encyclopedia of Historical Palaces, Vol 1, New York. Facts on File Publications, p.1.

Cervero, R. 1997. Paratransit in America. Praeger. 1.

Cervero, R. 1998. Paratransit: The gap fillers. Habitat Debate, vol.4, no.2.

Cervero, R. 2000. Informal transportation in the developing world. United Nations Centre for Human Settlement (Habitat), Nairobi.

Cervero, R. \& Golub, A. 2007. Informal transport: A global perspective. Transportation Policy, vol.4, issue 6, 445-57.

Dourado, A.B.F. 1995. Transporte 'Informal' X 'Formal' Verdaderia on Falsa Questao? Revista dos Transportes Publicos A no. 17, 66, 1 Trimetre. pp.81-91. ANTP, Sao Paulo.

Encyclopaedia Britannica. 20 January 2007.

Satiennam, T., Fukuda, A. \& Oshima, R. 2006. A study on the introduction of bus rapid transit system in Asian developing cities: A case study on Bangkok Metropolitan Administration Project. Journal of International Association of Traffic and Safety Sciences, vol. 30, no. 2, pp.59-69.

Shimazaki, T. \& Rahman, Md. M, 1996. Physical characteristics of paratransit in developing countries of Asia: Transportation in Asia-Pacific Countries Vol. 1. Journal of Advanced Transportation, vol.30, no.2, pp.5-24.

Tanaboriboon, Y. \& Agad, V.B. 1990. Bangkok's indispensable mode of public transport. Land Transport and Development International Conference, Dunkirk, 18-22 June, pp.341-46.

Tanaboriboon, Y. \& Madrona, L.G. 1990. Silor Leks: A novel solution to the mobility problems in the developing countries - a case study in Bangkok. Land Transport and Development International Conference, Dunkirk, 18-22 June, pp.347-52.

Umrigar, F., Sikdar, P.K. \& Khanna, K. 1991. Measuring the effectiveness of the urban bus system in India under existing organizational set ups. In PTRC: Urban Transport in Developing Countries, Lessons in Innovation, London, 160-69. 
Vuchic, V.R. 2007. Urban Transit Operations Planning and Economics. John Wiley \& Sons Inc, Hoboken, New Jersey. 